\title{
Common Health Problems of Retired Armed Forces Personnel Admitted In Combined Military Hospital, Dhaka
}

\author{
Khan MMI ${ }^{1}$, Haque $\mathrm{A}^{2}$, Rashid $\mathrm{R}^{3}$, Zafreen $\mathrm{F}^{4}$
}

DOI: https://doi.org/10.3329/jafmc.v15i1.48641

\begin{abstract}
Introduction: In Bangladesh there has been steady increase in aged (>60years) from $5.6 \%$ in the year 1981 to more than $7 \%$ in the year 2006 and $12 \%$ by the year 2025. In Armed Forces we have about 30 to $35 \%$ are of aged 60 years and above.Many of them are engaged in life struggle and nation-building activities. They deserve the healthy life access to all health facilities.

Objectives: To assess the common health problems of the retired Armed Forces Personnel and to find out necessary steps or quantify measures.

Materials and Methods: This was a descriptive type of cross sectional study conducted among the 112 retired Armed Forces Personnel who were admitted in Combined Military Hospital, Dhaka with a view to assess their health problems. The sample was selected purposively and data was collected by face to face interview.
\end{abstract}

Results: The mean age of the respondents was $59.20 \pm 7.22$ years. The most prevalent diseases among the respondents were hypertension (32.1\%), diabetes mellitus (17.0\%), bronchial asthma (13.4\%), ischemic heart disease $(10.7 \%)$, and cataract $(8.9 \%)$. Majority of respondents $(57.1 \%)$ were unemployed, $28.6 \%$ were engaged in business and $14.3 \%$ had a job in private company. The association between their health problems and present occupational status was found statistically highly significant $(p<0.05)$.

Conclusion: The most common health problems were hypertension, diabetes mellitus, bronchial asthma and ischemic heart disease among the retired Armed Forces personnel. Prevalence almost all the diseases were significantly $(p<0.05)$ associated with employment status.

Key-words: Retired armed forces personnel, Combined military hospital, Common health problems.

\section{Introduction}

Retirement and ageing are closely related though retirement does not have any specific age limit. For Bangladesh civil employee the retirement age is 59, in Armed Forces it is according to the rank and length of services. Though retirement from job indicates ageing but in Bangladesh socio-economic perspective ageing does not indicates retirement from struggle for life or retirement from productive activities or nation building activities. According to Bangladesh Bureau of Statistics, People above 60 years old are more than $35 \%$ in all divisions ${ }^{1}$. Steady increase in aged (>60years) from $5.6 \%$ in the year 1981 to more than $7 \%$ in the year 2006 and $12 \%$ by the year 2025 in Bangladesh ${ }^{2}$. The aged population in Bangladesh is growing both in absolute numbers and as a percentage of total population. The United Nations latest Population Projection for Bangladesh indicates that by the year 2025 the number of older persons is projected to grow to 16.2 million constituting $8.4 \%$ of total population ${ }^{2}$. The acceleration of population aging is expected to be exceptionally high between the year 2025 and 2050 as a result of which number of older persons in 2050 will reach $\mathbf{4 2 . 5}$ million. This would constitute $16 \%$ of the total national population, when one in every six persons will be an elderly person ${ }^{3}$. Decline in fertility and improvement in life expectancy from 45 years in 19721973 to 58 years in 1999-2000 have led to rapid increase in the number of older people in Bangladesh to about $7 \%$ of current population by the year 2020 expected to almost double ${ }^{4}$. Elderly in Bangladesh is an emerging issue. Migration, urbanization, the shift from extended/joint to nuclear families, lack of access to resources and other socio economic changes can marginalize older persons from the main stream of development, taking away their purposeful economic and social roles and weakening their traditional support ${ }^{5}$.

\section{Materials and Methods}

This descriptive cross sectional study was carried out at Combined Military Hospital $(\mathrm{CMH})$, Dhaka from 15 March to 30 June 2012. The respondents were retired Armed Forces Personnel admitted in this hospital. Inclusion criteria were who all were willing to participate in this study having only one disease. Verbal and written consent from the respondents were taken during the interview. Before data collection, the respondents were told that they were at liberty to participate and decline to answer any question during the study. Data was collected in a structured questionnaire by the researcher himself through face-to-face interview and analysis was done by SPSS 17.0 for windows.

\section{Results}

In this study out of 112 respondents, mean age was $59.20 \pm 7.22$ years and maximum $38(33.9 \%)$ was in age group $55-60$ years. Majority $64(57.1 \%)$ of the respondents were unemployed, where $32(28.6 \%)$ were engaged in business and $16(14.3 \%)$

1. Col Md Mazharul Islam Khan, MBBS, MPH, Commandant, CMH, Savar (E-mail: mik100883@yahoo.com) 2. Maj Ariful Haque, MBBS, DA, FCPS, Classified Anaesthesiologist, CMH, Savar. 3. Dr Rehnuma Rashid, MBBS, Diploma in Medical Ultrasonography, Consultant Sonologist, Comfort Diagnostic Centre, Uttara, Dhaka. 4. Dr Farzana Zafreen, MBBS, MPH, Associate Professor \& Head, Department of Community Medicine, Medical College for Women \& Hospital, Uttara, Dhaka. 
were service holders (Table-I). Among the respondents $36(32.1 \%)$ had hypertension (HTN), 12(10.7\%) had ischemic heart disease (IHD), 19(17.0\%) had diabetes mellitus (DM), 15(13.4\%) had bronchial asthma ( $\mathrm{Br}$ asthma), 9 (8.0\%) had benign enlargement of prostate (BEP), $10(8.9 \%)$ had cataract, $6(5.4 \%)$ had cancer and $5(4.5 \%)$ had arthritis. Among the respondents only $39(34.8 \%)$ were availing regular health checkup and $73(65.2 \%)$ did not go for regular health checkup. Most $65(58.1 \%)$ of the respondents seek treatment from $\mathrm{CMH}$, $38(33.9 \%)$ from private hospitals and $9(8 \%)$ from government hospitals. Regarding source of treatment fund $56(50.0 \%)$ were self-dependent, $42(37.5 \%), 7(6.3 \%)$ and $7(6.3 \%)$ were depending on son, daughter and wife respectively. (TableII). Respondents employment status had significant $(p<0.05)$ association with disease status; almost all the diseases were highly prevalent among respondents who were unemployed (Table-III). Source of treatment fund also had significant $(p<0.05)$ association with disease status (Table-IV)

Table-l: Distribution of respondents by socio-demographic characteristics $(n=112)$

\begin{tabular}{|l|l|c|c|}
\hline \multicolumn{1}{|c|}{ Characteristics } & & Frequency & Percentage \\
\hline \multirow{4}{*}{ Age in years } & $45-50$ & 16 & 14.3 \\
\cline { 2 - 4 } & $50-55$ & 20 & 17.9 \\
\cline { 2 - 4 } & $55-60$ & 38 & 33.9 \\
\cline { 2 - 4 } & $60-65$ & 19 & 17.0 \\
\cline { 2 - 4 } & Above 65 & 19 & 17.0 \\
\cline { 2 - 4 } & Mean $\pm S D=59.20 \pm 7.22$ \\
\hline \multirow{4}{*}{ Current Employment status } & Service & 16 & 14.3 \\
\cline { 2 - 4 } & Business & 32 & 28.6 \\
\cline { 2 - 4 } & Unemployed & 64 & 57.1 \\
\hline
\end{tabular}

Table-ll: Distribution of respondents by health related information $(\mathrm{n}=112)$

\begin{tabular}{|c|c|c|c|}
\hline \multicolumn{2}{|c|}{ Health related information } & Frequency & Percentage \\
\hline \multirow{8}{*}{$\begin{array}{l}\text { Common health } \\
\text { problems }\end{array}$} & Hypertension & 36 & 32.1 \\
\hline & Diabetes Mellitus & 19 & 17.0 \\
\hline & Ischemic heart diseases & 12 & 10.7 \\
\hline & Cancer & 6 & 5.4 \\
\hline & Cataract & 10 & 8.9 \\
\hline & Arthritis & 5 & 4.5 \\
\hline & Benign Enlargement of Prostate & 9 & 8.0 \\
\hline & $\mathrm{Br}$ asthma & 15 & 13.4 \\
\hline \multirow{2}{*}{$\begin{array}{l}\text { Regular health } \\
\text { checkup }\end{array}$} & Yes & 39 & 34.8 \\
\hline & No & 73 & 65.2 \\
\hline \multirow{3}{*}{$\begin{array}{l}\text { Place of usual } \\
\text { treatment }\end{array}$} & $\mathrm{CMH}$ & 65 & 58.1 \\
\hline & Govt. Hospital & 9 & 8.0 \\
\hline & Private hospital & 38 & 33.9 \\
\hline \multirow{4}{*}{$\begin{array}{l}\text { Source of } \\
\text { treatment fund }\end{array}$} & Self & 56 & 50 \\
\hline & Son & 42 & 37.5 \\
\hline & Daughter & 7 & 6.3 \\
\hline & Wife & 7 & 6.3 \\
\hline
\end{tabular}

Table-III: Association of respondents' health problems and present occupational status ( $\mathrm{n}-112)$.

\begin{tabular}{|c|c|c|c|c|}
\hline \multirow{2}{*}{ Health Problems } & \multicolumn{3}{|c|}{ Present Occupation } & \multirow{2}{*}{ Statistics } \\
\hline & Service & Business & Unemployed & \\
\hline HTN & $5(4.5)$ & $12(10.7)$ & $19(17.0)$ & \multirow{9}{*}{$\begin{array}{c}\chi 2=30.70 \\
d f=14 \\
p<0.05\end{array}$} \\
\hline DM & $0(0)$ & $10(8.9)$ & $9(8.0)$ & \\
\hline IHD & $2(1.8)$ & $3(2.7)$ & $7(6.3)$ & \\
\hline Cancer & $4(3.6)$ & $1(0.9)$ & $1(0.9)$ & \\
\hline Cataract & $0(0)$ & $2(1.8)$ & $8(7.1)$ & \\
\hline Arthritis & $1(0.9)$ & $1(0.9)$ & $3(2.7)$ & \\
\hline BEP & $0(0)$ & $1(0.9)$ & $8(7.1)$ & \\
\hline Bronchial asthma & $4(3.6)$ & $2(1.8)$ & $9(8.0)$ & \\
\hline Total & $16(14.3 \%)$ & $32(28.6 \%)$ & $64(57.1 \%)$ & \\
\hline
\end{tabular}

- Percentage in parenthesis

Table-IV: Association of respondents' health problems and source of treatment fund $(n=112)$

\begin{tabular}{|c|c|c|c|c|c|}
\hline \multirow{2}{*}{$\begin{array}{l}\text { Health } \\
\text { Problems }\end{array}$} & \multicolumn{4}{|c|}{ Source of treatment fund } & \multirow{2}{*}{ Statistics } \\
\hline & Self & Son & Daughter & Wife & \\
\hline HTN & $18(16.1 \%)$ & $16(14.3 \%)$ & $0(.0 \%)$ & $2(1.8 \%)$ & \multirow{9}{*}{$\begin{array}{c}\chi 2=33.83 \\
d f=21 \\
p<0.05\end{array}$} \\
\hline DM & $11(9.8 \%)$ & $5(4.5 \%)$ & $1(.9 \%)$ & $2(1.8 \%)$ & \\
\hline IHD & $9(8.0 \%)$ & $3(2.7 \%)$ & $0(.0 \%)$ & $0(.0 \%)$ & \\
\hline Cancer & $3(2.7 \%)$ & $3(2.7 \%)$ & $0(.0 \%)$ & $0(.0 \%)$ & \\
\hline Cataract & $1(.9 \%)$ & $8(7.1 \%)$ & $1(.9 \%)$ & $0(.0 \%)$ & \\
\hline Arthritis & $2(1.8 \%)$ & $1(.9 \%)$ & $2(1.8 \%)$ & $0(.0 \%)$ & \\
\hline BEP & $4(3.6 \%)$ & $2(1.8 \%)$ & $2(1.8 \%)$ & $1(.9 \%)$ & \\
\hline $\mathrm{Br}$ asthma & $8(7.1 \%)$ & $4(3.6 \%)$ & $1(.9 \%)$ & $2(1.8 \%)$ & \\
\hline Total & $56(50.0 \%)$ & $42(37.5 \%)$ & $7(6.3 \%)$ & $7(6.3 \%)$ & \\
\hline
\end{tabular}

- Percentage in parenthesis

\section{Discussion}

In this study $33.9 \%$ were in the age group of $55-60$ years and mean age was $59.20 \pm 7.22$ years which is consistent with the study of Salam et $\mathrm{al}^{6}$ and Stephen et $\mathrm{al}^{7}$. Among the study population prevalence of common health problems wereHTN (32.1\%), DM (17.0\%), Br asthma (13.4\%) IHD (10.7\%), cataract (8.9\%), BEP (8.0\%), cancer (5.4\%) and arthritis (4.5 $\%)$. This finding was not consistent with the studies of Hasan $\mathrm{T}^{8}$ where they found $29.2 \%$ gout, $19.7 \%$ heart disease, $19.7 \%$ skin disease and other than systemic problems weakness $79 \%$, eye sight $70 \%$ and denture problem about $31 \%$.This study revealed that $57.1 \%$ were unemployed, only $14.3 \%$ of respondents were found to have jobs in private company and $28.6 \%$ were engaged in business which is consistent with other study ${ }^{9}$. This indicates that these senior citizens still participate in economically productive activity. Regarding the disease prevalence almost all the diseases were highly prevalent among respondents who all were unemployedand suffered from hypertension (17.0\%), diabetes mellitus (8.0\%) Brasthma $(8.0 \%)$, cataract $(7.1 \%)$, benign prostatic hyperplasia $(7.1 \%)$ and IHD (6.3\%). Respondents who were involved in business were mostly suffered from HTN (10.7\%), DM (8.9\%), IHD (2.7\%) whereas cancer (3.6\%) was highly prevalent who were doing 
service. The association between their present occupation and common health problems was found statistically highly significant $(p<0.05)$.

Retired Armed Forces Personnel, in the past, were dignified and respected people of the society. At their extreme of age they are still dignified and self-sufficient. Among the respondents $(50.0 \%)$ were self-dependent whereas $(37.5 \%)$, $(6.3 \%)$ and $(6.3 \%)$ are depending on son, daughter and wife respectively. It shows that even today in our society sons extend to support to elderly parents, which also accord with the study of Chakleder $\mathrm{H}^{5}$, where they found traditionally primary responsibility for parents fall to the son who provides shelter and food. Majority of respondents (58.0\%) were getting health care from $\mathrm{CMH}^{9}$. This was may be due to better health care facilities and free of cost medical services. About $65.2 \%$ respondents usually did not go for regular health check-up. This may be due to the fact especially for rural respondents that difficulties to reach the CMHs, Govt. Hospitals \& private clinics which mostly located in urban areas. Financial incapability also another good reason for not availing regular health check-up.

\section{Conclusion}

The most common health problems were hypertension, diabetes mellitus, bronchial asthma and ischemic heart disease among the retired Armed Forces personnel. Majority $(57.1 \%)$ was unemployed and prevalence almost all the diseases were significantly $(p<0.05)$ associated with employment status. Among the respondents $50 \%$ were selfdependent for their treatment cost. The association between health problems and financial dependence was found statically significant $(p<0.05)$.Current data has supported to take appropriate measures to increase awareness as well as prevention and control of common health problems like hypertension, diabetes mellitus, bronchial asthma and ischemic heart disease among the retired Armed Forces personnel.

\section{References}

1. Bangladesh Bureau of Statistics, Nov 2015.

2. Hasina $\mathrm{C}$, Haque M, and Kabir M. Socio-economic situation of urban elderly population. Bangladesh Association of Gerontology. Dhaka; 2003:1.

3. Rashid KM, Khabir M, Hyder S. Textbook of Community Medicine and Public Health. 4th ed. Dhaka: RKH. 2004 chapter XXII:518-25.

4. Banu D. Health for Population Ageing. Bangladesh Perspective. The Elderly Contemporary Issue. Bangladesh Association of Gerontology 2003:79.

5. Chaklader $\mathrm{H}$, Haque M, Kabir. Baseline Survey on older people. BWHC 2004.

6. Salam MA and Kabir M. Boisko Bhata Scheme for Elderly Population: What are the Lessons Learned From it. The Elderly Contemporary Issues. Bangladesh Association of Gerontology. Dhaka; 2003:197.

7. Stephen et al. Ageing and Health Among Navajos Indians. Markides Ageing and Health. A Sage Focus Edition. Washington DC, 1985.

8. Hasan T. Study on Geriatric Problems in a Selected Community of Bangladesh. (Thesis). Dhaka: NIPSOM: 1998.

9. Literature and aging. The lancet 1999; 354(3):SIII1-SIII40. 